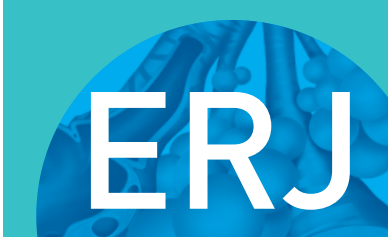

open research

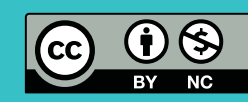

\section{Pulmonary hypertension in eosinophilic versus noneosinophilic COPD}

\author{
Bashar N. Alzghoul (1) ${ }^{1,2}$, Mohammad As Sayaideh², Brian F. Moreno², \\ Saminder K. Singh ${ }^{1,2}$, Ayoub Innabi ${ }^{1,2}$, Raju Reddy ${ }^{1,2}$, Eric S. Papierniak ${ }^{1,2}$ and \\ Hassan M Alnuaimat ${ }^{1,2}$
}

Affiliations: 'Division of Pulmonary, Critical Care and Sleep Medicine, University of Florida, Gainesville, FL, USA. ${ }^{2}$ Dept of Medicine, University of Florida, Gainesville, FL, USA.

Correspondence: Bashar Alzghoul, Division of Pulmonary, Critical Care and Sleep Medicine, Dept of Medicine, University of Florida, 1600 SW Archer Road, Box 100277, Gainesville, FL 32610, USA. E-mail: Bashar.alzghoulamedicine.ufl.edu

\section{ABSTRACT}

Background: The eosinophilic COPD phenotype is associated with greater airway remodelling, exacerbation risk and steroid responsiveness. However, little is known about the prevalence and characteristics of pulmonary hypertension $(\mathrm{PH})$ in this patient population.

Methods: We retrospectively evaluated a cohort of COPD patients with right heart catheterisation (RHC) data at a university hospital between January 2011 and May 2019 and compared the pulmonary vascular profile and prevalence of $\mathrm{PH}$ between eosinophilic and noneosinophilic patients using a definition of eosinophilic COPD as at least three blood eosinophil values $\geqslant 300$ cells $\mu \mathrm{L}^{-1}$. We used multivariable logistic regression analyses to examine the association between eosinophilic COPD and various $\mathrm{PH}$ categories adjusting for age, sex, body mass index, forced expiratory volume in $1 \mathrm{~s}$ (\%), smoking status and use of supplemental oxygen.

Results: Among 106 COPD patients with RHC data and at least three blood eosinophil values, 25\% met the definition of eosinophilic COPD. Fewer patients among the eosinophilic group required long-term oxygen therapy $(69 \%$ versus $93 \%, \mathrm{p}=0.001)$ and total lung capacity was significantly lower in the eosinophilic group ( $\mathrm{p}=0.006$ ). This group had higher mean pulmonary arterial pressure (mPAP) (median (interquartile range) $30(27-41) \mathrm{mmHg}$ versus $25(22-30) \mathrm{mmHg}, \mathrm{p}=0.001)$ and pulmonary vascular resistance (PVR) (4 (2.8-5.1) Wood units versus 2.9 (2.1-4.1) Wood units, $\mathrm{p}=0.018$ ). On multivariable logistic regression analyses, eosinophilic phenotype was associated with PH (adjusted (a)OR 6.5, 95\% CI 1.4-30.7; $\mathrm{p}=0.018$ ) and pre-capillary PH (aOR 3.2, 95\% CI 1.1-9; $\mathrm{p}=0.027)$, but not severe PH (aOR 2.1, 95\% CI 0.6-7.2; $\mathrm{p}=0.219)$.

Conclusion: Eosinophilic COPD was associated with higher mPAP and PVR and increased likelihood of $\mathrm{PH}$. More studies are needed to further explore this finding.

@ERSpublications

In COPD patients with right heart catheterisation, eosinophilic COPD confers a 7-fold increase in the likelihood of pulmonary hypertension and a 3-fold increase in the likelihood of precapillary pulmonary hypertension compared to noneosinophilic COPD https://bit.ly/2YJk7aB

Cite this article as: Alzghoul BN, As Sayaideh M, Moreno BF, et al. Pulmonary hypertension in eosinophilic versus noneosinophilic COPD. ERJ Open Res 2021; 7: 00772-2020 [https://doi.org/ 10.1183/23120541.00772-2020].

This article has supplementary material available from openres.ersjournals.com.

Received: 22 Oct 2020 | Accepted after revision: 27 Jan 2021

Copyright $\odot$ The authors 2021. This version is distributed under the terms of the Creative Commons Attribution NonCommercial Licence 4.0. For commercial reproduction rights and permissions contact permissions@ersnet.org 


\section{Introduction}

COPD is projected to be the third leading cause of death worldwide by 2030 [1]. The presence of pulmonary hypertension (PH) in COPD has a stronger association with mortality compared to pulmonary function test (PFT) parameters such as forced expiratory volume in $1 \mathrm{~s}\left(\mathrm{FEV}_{1} \%\right)$ or gas exchange variables $[2,3]$. $\mathrm{PH}$ has been defined as mean pulmonary artery pressure $(\mathrm{mPAP}) \geqslant 25 \mathrm{mmHg}$, but this has been revised in chronic lung disease patients (CLD-PH) into those with mPAP 21-24 mmHg with pulmonary vascular resistance (PVR) $\geqslant 3$ Wood units (WU) or $\mathrm{mPAP} \geqslant 25 \mathrm{mmHg}$ [3]. The prevalence of $\mathrm{PH}$ in COPD is probably underestimated, as most data were derived from patients with severe disease undergoing lung transplant evaluation. Several studies have shown that up to $90 \%$ of patients with Global Initiative for Chronic Obstructive Lung Disease (GOLD) stage IV have mPAP $>20 \mathrm{mmHg}$ and $\sim 5 \%$ of COPD patients have mPAP $>35-40 \mathrm{mmHg}$ at rest $[3,4]$.

Eosinophilic COPD has been increasingly recognised as a distinct phenotype. The 2019 GOLD report introduced the blood eosinophil count as a biomarker to start or de-escalate inhaled corticosteroids [5]. Thresholds for eosinophilia assessed by different studies included relative eosinophil count of $2 \%$, and absolute eosinophil counts of 150,300 and 340 cells $\mu \mathrm{L}^{-1}$ [6]. Using a cut-off of 300 cells $\mu \mathrm{L}^{-1}, 20 \%$ of COPD patients were reported to have an eosinophilic phenotype [7]. The role of eosinophils in the development of pulmonary arterial hypertension (PAH) has been demonstrated in few animal [8-10] and human studies [11-13]. However, to our knowledge, no previous study has evaluated PH specifically in eosinophilic COPD patients.

\section{Methods}

We retrospectively evaluated a cohort of COPD patients who underwent right heart catheterisation (RHC) for evaluation of PH at the University of Florida between January 2011 and May 2019. We compared the pulmonary haemodynamic profile and prevalence of $\mathrm{PH}$ between patients with eosinophilic and noneosinophilic COPD. Study was approved by the University of Florida institutional review board (IRB 201901525).

\section{Study subjects and clinical variables}

We initially identified 119 patients previously diagnosed with COPD who also had available RHC data. The indication for RHC was either lung pre-transplant work-up or suspected PH. Information was collected about baseline characteristics, comorbidities, PFTs, echocardiogram, RHC, 6-min walk distance (6MWD), imaging and laboratory data. A board-certified pulmonary attending (HA) and a pulmonary fellow (BNA) reviewed the patients' chest computed tomography (CT) scans and PFTs and excluded patients who were mislabelled as COPD or had underlying interstitial lung disease (ILD). COPD was defined per the American Thoracic Society (ATS)/European Respiratory Society guidelines [14]. One patient did not have spirometry available, but had significant emphysema on chest CT and was included in the analysis [15]. Nine patients (previously labelled to have COPD, but did not have any spirometric or radiological evidence of COPD, or had underlying ILD), were excluded, bringing the final number to 111 patients: 92 who underwent RHC for pre-transplant work-up and 19 for suspected PH. Vital signs were obtained on the day of RHC. Laboratory values closest to the RHC date were reported.

We classified the patients into eosinophilic versus noneosinophilic COPD. Eosinophilia was defined as having at least three absolute blood eosinophil counts $\geqslant 300$ cells $\mu \mathrm{L}^{-1}[5,6,16,17]$. We only included patients who had at least three separate complete blood count (CBC) results available (106 patients).

\section{COPD severity parameters and PFT}

Post-bronchodilator spirometry, plethysmography and diffusing capacity of the lung for carbon monoxide $\left(D_{\mathrm{LCO}}\right)$ data were collected for each patient (Zan 500 Body; nSpire Health, Louisville, CO, USA). These were performed according to ATS guidelines [18] using predicted values according to the third National Health and Nutrition Examination Survey [19]. PFT values were not available in one (0.9\%) patient. Patients were classified into four classes based on airflow limitation according to the GOLD 2020 report [5]. In addition, we compared supplemental oxygen for each patient, smoking history, $\alpha_{1}$-antitrypsin deficiency, 6MWD, BODE (body mass index, airflow obstruction, dyspnoea and exercise) COPD severity index, New York Heart Association functional classification and number of COPD exacerbations requiring hospitalisation in the previous year.

\section{Echocardiography}

Transthoracic echocardiography was performed using a Philips EPIQ 7 system (Philips Healthcare, Andover, MA, USA). We used echocardiographic values measured as described in the American Society of Echocardiography guidelines [20] as reported by board-certified cardiologists. The echocardiogram closest 
in time to the RHC was selected. The median time difference between obtaining the echocardiogram and RHC was 3 days (interquartile range (IQR) 1-46 days).

\section{Right heart catheterisation}

RHC was performed by a board-certified cardiologist or pulmonologist as part of the lung transplantation evaluation $(82.9 \%)$ and/or if they had clinical suspicion for PH (17.1\%). The majority of RHCs (90\%) were performed as outpatient cases with no statistically significant difference between the two groups, and only one patient in each group was being treated for COPD exacerbation when the RHC was performed. End-expiration values were recorded. Cardiac output was measured using either the thermodilution $(74.8 \%)$ or indirect Fick method (25.2\%) [21]. PVR was calculated as (mPAP - pulmonary capillary wedge pressure (PCWP))/cardiac output expressed in Wood units. Diastolic pulmonary gradient was calculated as the difference between the diastolic pulmonary artery pressure and PCWP [22]. We defined $\mathrm{PH}$ as $\mathrm{mPAP} \geqslant 25 \mathrm{mmHg}$ [2] and reported the prevalence of $\mathrm{PH}$ as per the 2018 World Symposium on Pulmonary Hypertension (WSPH) consensus definition of CLD-PH (mPAP 21-24 mmHg with PVR $\geqslant 3 \mathrm{WU}$, or $\mathrm{mPAP} \geqslant 25 \mathrm{mmHg}$ ) [3]. Pre-capillary $\mathrm{PH}$ was defined as $\mathrm{mPAP} \geqslant 25 \mathrm{mmHg}$, PVR $\geqslant 3 \mathrm{WU}$ and PCWP $\leqslant 15 \mathrm{mmHg}$, and severe $\mathrm{PH}$ as $\mathrm{mPAP} \geqslant 35 \mathrm{mmHg}$ or $25-34 \mathrm{mmHg}$ with cardiac index) $<2 \mathrm{~L} \cdot \mathrm{min}^{-1} \cdot \mathrm{m}^{-2}[3]$.

\section{Sensitivity analysis}

We performed a subgroup analysis comparing eosinophilic and noneosinophilic COPD using only the pre-transplant cohort (92 patients). Additionally, we ran the analysis using an alternative definition of eosinophilic COPD as a single blood eosinophil count $\geqslant 340$ cells. $\mu \mathrm{L}^{-1}$ [23] (111 patients). Furthermore, using a definition of $\mathrm{PH}$ as $\mathrm{mPAP} \geqslant 25 \mathrm{mmHg}$, we determined the prevalence of eosinophilia in those with and without $\mathrm{PH}$.

\section{Statistical analysis}

We summarised the data as percentages for categorical variables, mean $\pm \mathrm{SD}$ for normally distributed continuous variables and median (IQR) for non-normally distributed continuous variables. Shapiro-Wilk testing and visual inspection of variables' histograms were used to assess distribution normality. An independent-sample t-test was used to compare variables with normal distribution and the Mann-Whitney U-test was used for variables with non-normal distribution. We constructed a clustered bar chart to demonstrate the prevalence rates of $\mathrm{PH}$ and its subgroups in eosinophilic versus noneosinophilic COPD. We used multivariable logistic regression analyses to examine the association between eosinophilic COPD and various $\mathrm{PH}$ categories. In multivariable models, we adjusted for age, sex, body mass index (BMI) [24], $\mathrm{FEV}_{1} \%$, smoking status (active versus former) and need for supplementary oxygen during RHC, which were chosen on an a priori basis. We then presented the adjusted odds ratio (95\% confidence interval) of having various $\mathrm{PH}$ categories in eosinophilic versus noneosinophilic COPD. Statistical analyses were performed using IBM SPSS Statistics for Windows (version 23.0; released 2015, IBM Corp, Armonk, NY, USA).

\section{Results}

111 patients with confirmed diagnosis of COPD who also had RHC were identified, of whom 106 had at least three $\mathrm{CBC}$ values and were included in the primary analysis. 26 (24.5\%) patients met the definition of eosinophilic COPD. Both groups were generally middle-aged Caucasians and almost equally distributed between males and females (table 1). Eosinophilic patients had higher BMI $(\mathrm{p}=0.006)$, more history of rheumatological diseases $(p=0.045)$ and were marginally more likely to have a history of marijuana smoking and diabetes mellitus ( $\mathrm{p}=0.052$ and 0.057 , respectively). There were no significant differences in other comorbidities (table 1).

There were no significant differences in $\mathrm{FEV}_{1}$ (median (IQR) 24\% (19-48\%) versus 21\% (17-26\%), $\mathrm{p}=0.101$ ) or GOLD airflow limitation severity. Fewer patients among the eosinophilic group required long-term supplemental oxygen therapy $(69 \%$ versus $93 \%, \mathrm{p}=0.001)$. Furthermore, total lung capacity (TLC) was significantly lower in the eosinophilic COPD group $(\mathrm{p}=0.006)$ (table 2). There were no statistically significant differences between the two groups in the use of inhaled corticosteroids (77\% versus $85 \%, \mathrm{p}=0.341)$, chronic oral steroid therapy ( $23 \%$ versus $17.5 \%, \mathrm{p}=0.528)$ or chronic azithromycin therapy ( $7.7 \%$ versus $10 \%, \mathrm{p}=0.727$ ). Roflumilast use was more common in the eosinophilic COPD group, but did not reach statistical significance $(23 \%$ versus $10 \%, \mathrm{p}=0.087)$. There was no statistically significant difference in any other COPD-related measured values (table 2).

The reported echocardiographic parameters are summarised in table 3. Eosinophilic COPD patients had more left atrial dilation $(27 \%$ versus $10 \%, \mathrm{p}=0.039)$ and marginally more left ventricular hypertrophy (did not reach statistical significance, $\mathrm{p}=0.059)$. There was no statistically significant difference in the other 


\begin{tabular}{|c|c|c|c|}
\hline & Eosinophilic COPD & Noneosinophilic COPD & p-value \\
\hline Patients $\mathrm{n}$ & 26 & 80 & \\
\hline \multicolumn{4}{|l|}{ Demographics } \\
\hline Age years & $64 \pm 7.4$ & $61.3 \pm 7.7$ & 0.124 \\
\hline Female & $12(46.2)$ & 45 (56.3) & 0.370 \\
\hline \multicolumn{4}{|l|}{ Race } \\
\hline Caucasian & 24 (92.3) & 75/79 (94.9) & \multirow[t]{2}{*}{0.616} \\
\hline African-American & $2(7.7)$ & $4 / 79(5.1)$ & \\
\hline \multicolumn{4}{|l|}{ Clinical characteristics } \\
\hline Body mass index $\mathrm{kg} \cdot \mathrm{m}^{-2}$ & $27 \pm 4.3$ & $24.3 \pm 4.3$ & 0.006 \\
\hline Heart rate beats $\cdot \min ^{-1 \pi}$ & $81.3 \pm 15.5$ & $80.8 \pm 12.3$ & 0.868 \\
\hline Oxygen saturation $\%$ ? & $96.3 \pm 2.3$ & $97.3 \pm 2.7$ & 0.093 \\
\hline Mean systemic blood pressure $\mathrm{mmHg}^{\text {ๆ }}$ & $96.5 \pm 14.4$ & $99 \pm 11.7$ & 0.377 \\
\hline Marijuana use & $7(26.9)$ & 9 (11.3) & 0.052 \\
\hline Asthma & $1(3.8)$ & $3(3.8)$ & 0.682 \\
\hline Atopic dermatitis & $3(11.5)$ & $3(3.8)$ & 0.156 \\
\hline Systemic hypertension & $14(53.8)$ & $44(55)$ & 0.918 \\
\hline Diabetes mellitus & 10 (38.5) & $16(20)$ & 0.057 \\
\hline Congestive heart failure & $2(7.7)$ & $7(8.8)$ & 0.867 \\
\hline Obstructive sleep apnoea & $4(15.4)$ & 9 (11.3) & 0.577 \\
\hline Rheumatological disease $^{+}$ & $3(11.5)$ & $1(1.3)$ & 0.045 \\
\hline \multicolumn{4}{|l|}{ Laboratory findings ${ }^{\pi}$} \\
\hline WBC $\times 10^{9}$ cells $\cdot L^{-1}$ & $8.5 \pm 2.7$ & $8.7 \pm 3.6$ & 0.820 \\
\hline$P_{\mathrm{aO}_{2}} \mathrm{mmHg} \mathrm{gl}^{\mathrm{T}}$ & $83(77-89)$ & 80 (69-91) & 0.541 \\
\hline Eosinophils cells $\mu \mathrm{L}^{-1}$ & $333.5 \pm 189.6$ & $164.6 \pm 70$ & $<0.001$ \\
\hline Brain natriuretic peptide $\mathrm{pg} \cdot \mathrm{mL}^{-1}$ & $75.1(16-184)$ & $37.1(20-122)$ & 0.881 \\
\hline \multicolumn{4}{|c|}{$\begin{array}{l}\text { Data are presented as } \mathrm{n}, \text { mean } \pm \mathrm{SD}, \mathrm{n}(\%), \mathrm{n} / \mathrm{N}(\%) \text { or median (interquartile range), unless otherwise stated. } \\
\text { WBC: white blood cells; } P_{\mathrm{aO}_{2}} \text { : arterial oxygen tension. }{ }^{\#} \text { : eosinophilic COPD was defined as having at least } \\
\text { three separate absolute blood eosinophil counts } \geqslant 300 \text { cells. } \mu \mathrm{L}^{-1} \text {. Five patients did not have at least three } \\
\text { eosinophil count values and were not classified based on this definition; }{ }^{\eta}: \text { vital signs were reported on the } \\
\text { day of right heart catheterisation (RHC). Lab measures closest to the RHC date were reported. } P_{\mathrm{aO}_{2}} \text { on the } \\
\mathrm{RHC} \text { day was only available in } 26 \% \text { of the patients; }{ }^{+} \text {: of the three patients in the eosinophilic group with } \\
\text { rheumatological disorders, one had rheumatoid arthritis with relapsing polychondritis (mean pulmonary } \\
\text { arterial pressure (mPAP) } 40 \mathrm{mmHg} \text { ), one had systemic lupus erythematosus (SLE) (mPAP } 32 \mathrm{mmHg} \text { ) and } \\
\text { one had scleroderma (mPAP } 55 \mathrm{mmHg} \text { ), and the one patient from the noneosinophilic group had SLE } \\
\text { (mPAP } 21 \mathrm{mmHg} \text { ). All of these four patients underwent RHC for pulmonary hypertension evaluation and } \\
\text { were not pre-transplant patients. }\end{array}$} \\
\hline
\end{tabular}

echocardiographic parameters. On RHC, the eosinophilic patients had higher systolic and diastolic pulmonary artery pressures ( $\mathrm{p}=0.004$ and 0.046 , respectively), higher mPAP (median (IQR) 30 (27-41) mmHg versus 25 (22-30) mmHg, $\mathrm{p}=0.001)$ and higher PVR (4 (2.8-5.1) WU versus 2.9 (2.1-4.1) WU, $\mathrm{p}=0.018$ ). There was no statistically significant difference in PCWP, cardiac output and cardiac index (table 3 ).

On univariable analysis, eosinophilic patients had more PH (OR 8, 95\% CI 1.8-36.2; p=0.002), CLD-PH (2018 WSPH definition) $(6.1,1.3-27.8 ; \mathrm{p}=0.01)$, pre-capillary $\mathrm{PH}(3.3,1.3-8.3 ; \mathrm{p}=0.01)$ and marginally more severe $\mathrm{PH}(2.5,0.96-6.5 ; \mathrm{p}=0.057)$ (figure 1$)$. On multivariable logistic regression adjusting for potential confounders, this phenotype was associated with PH (adjusted (a)OR 6.9, 95\% CI 1.5-32.4; $\mathrm{p}=0.015)$ and pre-capillary PH (aOR 3.3, 95\% CI 1.2-9.1; $\mathrm{p}=0.023)$, but not with severe PH (aOR 1.7, 95\% CI 0.5-5.3; $\mathrm{p}=0.365)$ (table 4).

Using the same definition of eosinophilic COPD, but including pre-transplant patients only, the eosinophilic group had higher mPAP $(\mathrm{p}=0.008)$ but not PVR $(\mathrm{p}=0.108)$. Additionally, they had more $\mathrm{PH}$ ( $89 \%$ versus $56 \%, \mathrm{p}=0.011)$ and $\mathrm{CLD}-\mathrm{PH}(89 \%$ versus $62 \%, \mathrm{p}=0.030)$, but not pre-capillary or severe $\mathrm{PH}$ ( $\mathrm{p}=0.108$ and 0.224 , respectively) (supplementary table $\mathrm{S} 1$ ). Using a single eosinophil count of $\geqslant 340$ cells $\mu \mathrm{L}^{-1}$ to define eosinophilic COPD, eosinophilic patients had higher mPAP $(p=0.013)$ and PVR $(\mathrm{p}=0.047)$, more $\mathrm{PH}(\mathrm{p}=0.016), \mathrm{CLD}-\mathrm{PH}(\mathrm{p}=0.019)$ and pre-capillary $\mathrm{PH}(\mathrm{p}=0.036)$, but not severe $\mathrm{PH}$ $(\mathrm{p}=0.164)$ (supplementary table $\mathrm{S} 2$ ). Comparing patients with and without $\mathrm{PH}, \mathrm{COPD}-\mathrm{PH}$ patients had higher blood eosinophil counts measured closest in time to the RHC ( $p=0.046)$, had marginally higher 


\begin{tabular}{|c|c|c|c|}
\hline & Eosinophilic COPD & Noneosinophilic COPD & p-value \\
\hline Patients & 26 & 80 & \\
\hline Long-term supplemental oxygen use & $18(69.2)$ & $71 / 76(93.4)$ & 0.001 \\
\hline Supplemental oxygen during RHC & $21(81)$ & $66 / 79$ (83.5) & 0.754 \\
\hline Active smokers & 0 & $2(2.5)$ & 0.416 \\
\hline Smoking pack-years & $36.8(25-61.1)$ & $40(30-60)$ & 0.390 \\
\hline$\alpha_{1}$-antitrypsin deficiency & $4 / 18(22.2)$ & $6 / 60(10)$ & 0.174 \\
\hline 6-min walk distance $\mathrm{m} \pi$ & $226 \pm 102.9$ & $240.6 \pm 107.9$ & 0.554 \\
\hline BODE index & $6(5-8)$ & $7(6-8)$ & 0.104 \\
\hline NYHA class" & 3 & 3 & 0.074 \\
\hline COPD exacerbations in past year" & $1(0-2)$ & $1(0-2)$ & 0.784 \\
\hline Inhaled corticosteroids use & $20(77)$ & $68(85)$ & 0.341 \\
\hline Chronic azithromycin use & $2(7.7)$ & $8(10)$ & 0.727 \\
\hline Roflumilast use & $6(23)$ & $8(10)$ & 0.087 \\
\hline Chronic oral steroids use ${ }^{+}$ & 6 (23) & $14(17.5)$ & 0.528 \\
\hline \multicolumn{4}{|l|}{ Pulmonary function tests $\pi$} \\
\hline $\mathrm{FEV}_{1} \%$ pred & $24(19-48)$ & $21(16.9-26.3)$ & 0.101 \\
\hline FVC \% pred & $56 \pm 16.9$ & $53.2 \pm 17$ & 0.454 \\
\hline $\mathrm{FEV}_{1} / \mathrm{FVC} \%$ & $34(28.1-60.5)$ & $32(26-39)$ & 0.121 \\
\hline Positive bronchodilator response $\mathrm{n} / \mathrm{N}(\%)$ & $1 / 23(4.3)$ & $6 / 65(9.2)$ & 0.457 \\
\hline TLC $\%$ pred & $96.5 \pm 25.5$ & $117.9 \pm 27.2$ & 0.006 \\
\hline$D_{\mathrm{LCO}_{\mathrm{Hb}}} \%$ pred & $29.5(20.3-46.3)$ & $24.7(18.5-34)$ & 0.226 \\
\hline \multicolumn{4}{|l|}{ GOLD airflow limitation severity $\mathrm{n} / \mathrm{N}(\%)$} \\
\hline GOLD 1 (FEV ${ }_{1} \geqslant 80 \%$ pred) & 0 & $3 / 79$ (3.8) & 0.422 \\
\hline GOLD $2\left(50 \% \leqslant \mathrm{FEV}_{1}<80 \%\right.$ pred) & $6(23.1)$ & $4 / 79(5.1)$ & 0.007 \\
\hline GOLD $3\left(30 \% \leqslant F E V_{1}<50 \%\right.$ pred) & 3 (11.5) & $9 / 79(11.4)$ & 0.984 \\
\hline GOLD 4 (FEV $1<30 \%$ pred) & $17(65.4)$ & $63 / 79(79.7)$ & 0.136 \\
\hline
\end{tabular}

Data are presented as $n, n(\%), n / N(\%)$, median (interquartile range) or mean $\pm S D$, unless otherwise stated. RHC: right heart catheterisation; BODE: body mass index, airflow obstruction, dyspnoea and exercise COPD severity index; NYHA: New York Heart Association functional class; $F_{1} V_{1}$ : forced expiratory volume

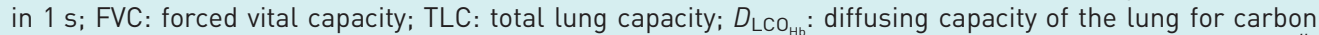
monoxide corrected for haemoglobin; GOLD: Global Initiative for Chronic Obstructive Lung Disease. \#: eosinophilic COPD was defined as having at least three separate absolute blood eosinophil counts $\geqslant 300$ cells $\mu \mathrm{L}^{-1}$. Five patients did not have at least three eosinophil count values and were not classified based on this definition; ๆ: information regarding 6-min walk distance, BODE index, NYHA and COPD exacerbations was available in $97.1 \%, 92.4 \%, 94.3 \%$ and $62.2 \%$ of the patients, respectively. Data regarding $\mathrm{FEV}_{1} \%, \mathrm{FVC}$ and $\mathrm{FEV}_{1} / \mathrm{FVC}$ ratio were available in $99.2 \%$ of the patients. Data regarding TLC and $D_{\mathrm{LCO}_{\mathrm{Hb}}}$ were available for $74.5 \%$ and $76.4 \%$ of the patients, respectively; ${ }^{+}$: oral prednisone doses ranged from $2.5 \mathrm{mg}$ daily to $10 \mathrm{mg}$ daily.

maximum counts $(\mathrm{p}=0.050)$ and were more likely to have an eosinophilic phenotype using either definition (table 5).

\section{Discussion}

In our study, eosinophilic COPD phenotype was associated with elevated mPAP and an increased likelihood of $\mathrm{PH}$ and pre-capillary $\mathrm{PH}$ compared to patients with noneosinophilic COPD. On multivariable analyses adjusting for potential confounders, eosinophilic phenotype conferred a seven-fold increase in the likelihood of $\mathrm{PH}$ and a three-fold increase in the likelihood of pre-capillary $\mathrm{PH}$. In addition, one-third of the patients with confirmed COPD-PH had eosinophilia, compared to $6 \%$ of the COPD-no-PH group.

A growing body of evidence has identified eosinophilic COPD as a distinct phenotype $[6,25]$ and the use of peripheral eosinophilia as a biomarker to predict steroid responsiveness in COPD patients has been supported by several studies [7, 26-30]. Based on these findings, the GOLD guidelines recommend the use of an absolute eosinophil count $\geqslant 300$ cells $\mu \mathrm{L}^{-1}$ as a cut-off to add or stop inhaled corticosteroids [5]. However, to our knowledge, this is the first study to investigate the pulmonary vascular haemodynamic profile of the eosinophilic COPD phenotype and its association with $\mathrm{PH}$. 


\begin{tabular}{|c|c|c|c|}
\hline & Eosinophilic COPD & Noneosinophilic COPD & p-value \\
\hline Patients & 26 & 80 & \\
\hline \multicolumn{4}{|l|}{ Echocardiogram } \\
\hline Ejection fraction \% & $60(60-65)$ & $65(60-65)$ & 0.193 \\
\hline Diastolic dysfunction & $5 / 25(20)$ & $15 / 77$ (19.5) & 0.955 \\
\hline Left ventricular dilation & 1 (3.8) & $1(1.3)$ & 0.398 \\
\hline Left ventricular hypertrophy & 3 (11.5) & $2(2.5)$ & 0.059 \\
\hline Left atrial dilation & $7(26.9)$ & $8 / 77(10.4)$ & 0.039 \\
\hline Right ventricular dilation & $8(30.8)$ & $22(27.5)$ & 0.748 \\
\hline Right ventricular hypertrophy & 0 & $4(5.1)$ & 0.314 \\
\hline Right atrial dilation & $5(19.2)$ & $14 / 75(18.7)$ & 0.949 \\
\hline RVSP $\mathrm{mmHg}$ & $56.7 \pm 19.9$ & $50.7 \pm 24$ & 0.473 \\
\hline Tricuspid regurgitation velocity $\mathrm{m} \cdot \mathrm{s}^{-1}$ & $3.5 \pm 0.6$ & $3.2 \pm 0.7$ & 0.277 \\
\hline TAPSE mm & 20 (19-20) & 20 & 0.789 \\
\hline \multicolumn{4}{|l|}{ Right heart catheterisation parameters } \\
\hline Systolic pulmonary artery pressure $\mathrm{mmHg}$ & $45.5(35.8-62.5)$ & 37.5 (32-43.8) & 0.004 \\
\hline Diastolic pulmonary artery pressure $\mathrm{mmHg}$ & $20.5(19.5-30.3)$ & $20(15-24.8)$ & 0.046 \\
\hline Mean pulmonary artery pressure $\mathrm{mmHg}$ & $30(26.8-40.8)$ & $25(22-30)$ & 0.001 \\
\hline PCWP mmHg & $14.7 \pm 4.5$ & $13 \pm 4.3$ & 0.096 \\
\hline Right atrial pressure $\mathrm{mmHg}$ & $10.2 \pm 4.7$ & $9.4 \pm 3.8$ & 0.353 \\
\hline Diastolic pulmonary gradient $\mathrm{mmHg}$ & $10(3-13.5)$ & $5(3-10)$ & 0.064 \\
\hline Pulmonary vascular resistance $\mathrm{mmHg}$ & $4(2.8-5.1)$ & $2.9(2.1-4.1)$ & 0.018 \\
\hline Cardiac output L. $\mathrm{min}^{-1}$ & $4.3(4-4.9)$ & $4.2(3.4-4.9)$ & 0.394 \\
\hline Cardiac index $\mathrm{L} \cdot \mathrm{min}^{-1} \cdot \mathrm{m}^{-2}$ & $2.4(2.2-2.6)$ & $2.2(2-2.6)$ & 0.760 \\
\hline
\end{tabular}

Data are presented as $n$, median (interquartile range), $n / N(\%), n(\%)$ or mean $\pm S D$, unless otherwise stated. RVSP: right ventricular systolic pressure; TAPSE: tricuspid annular plane systolic excursion; PCWP: pulmonary capillary wedge pressure. \#: eosinophilic COPD was defined as having at least three separate absolute blood eosinophil counts $\geqslant 300$ cells $\mu \mathrm{L}^{-1}$. Five patients did not have at least three eosinophil count values and were not classified based on this definition.

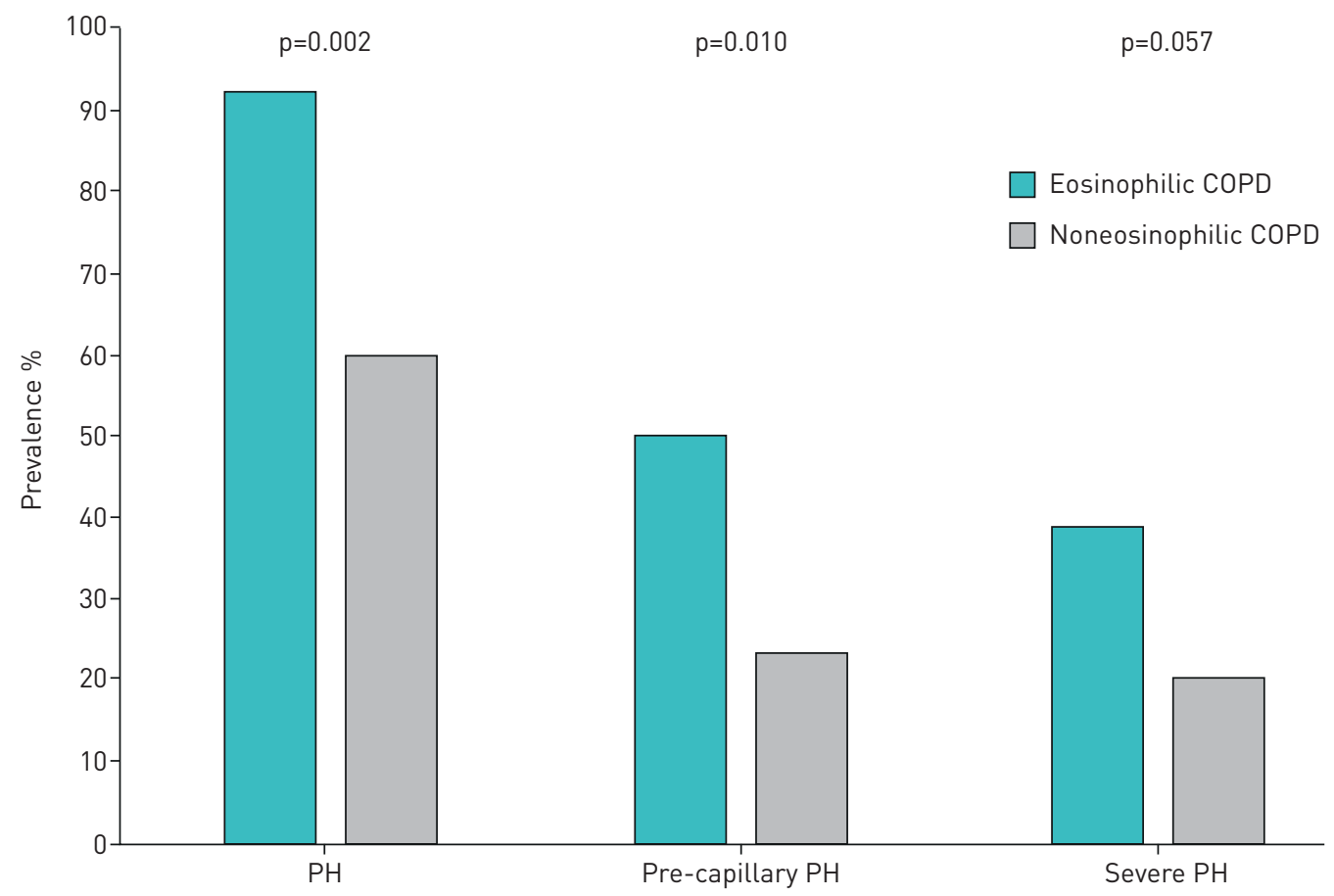

FIGURE 1 Clustered-bar chart demonstrating the prevalence of pulmonary hypertension (PH), pre-capillary $\mathrm{PH}$ and severe $\mathrm{PH}$ in patients with eosinophilic COPD as compared to noneosinophilic COPD patients. 


\begin{tabular}{|c|c|c|c|c|c|}
\hline & $\begin{array}{l}\text { Eosinophilic } \\
\text { COPD }\end{array}$ & $\begin{array}{l}\text { Noneosinophilic } \\
\text { COPD }\end{array}$ & p-value & $\begin{array}{l}\text { Adjusted } \\
\text { p-value }\end{array}$ & $\begin{array}{l}\text { Adjusted OR } \\
\text { (95\% CI) }\end{array}$ \\
\hline Patients & 26 & 80 & & & \\
\hline $\mathrm{PH}^{\pi}$ & 24 (92.3) & $48(60)$ & 0.002 & 0.018 & $6.5(1.4-30.7)$ \\
\hline $\begin{array}{l}\text { CLD-PH per the } \\
\text { WSPH } 2018^{+}\end{array}$ & 24 (92.3) & $53(66.3)$ & 0.010 & 0.041 & $5.1(1.1-23.9)$ \\
\hline Pre-capillary $\mathbf{P H}^{\S}$ & $13(50)$ & 18/77 (23.4) & 0.010 & 0.027 & $3.2(1.1-9)$ \\
\hline Severe $\mathrm{PH}^{f}$ & 10 (38.5) & $16(20)$ & 0.057 & 0.219 & $2.1(0.6-7.2)$ \\
\hline \multicolumn{6}{|c|}{ 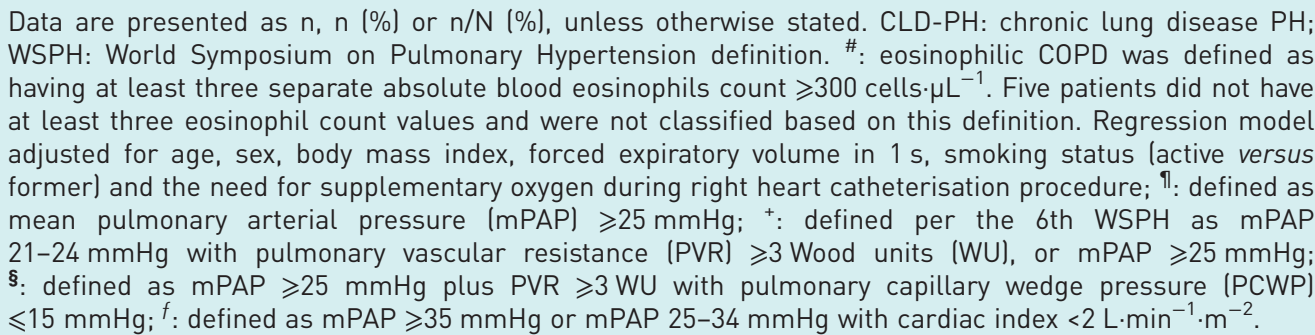 } \\
\hline
\end{tabular}

The previously reported prevalence of eosinophilic COPD ranges from $\sim 20 \%$ to $70 \%$, depending on the threshold used and the patient population studied [31]. In a post hoc analysis of the WISDOM trial, $20 \%$ of the COPD patients had eosinophils $\geqslant 300$ cells. $\mu \mathrm{L}^{-1}$ [7], which is close to what we found in our study using the same cut-off (24.5\%). However, we chose to use three eosinophil counts, as these tend to be unstable and using one measurement to define the eosinophilic COPD phenotype has been questioned before $[6,32]$. In addition, the slightly higher BMI we found in our cohort is similar to that which has been reported in eosinophilic COPD, as is the similarity in GOLD airflow limitation between the two groups [31]. The eosinophilic patients had a significantly lower TLC, which could indicate that they had less hyperinflation and emphysema, although we did not quantify the degree of emphysema on computed tomography. This finding might be in line with a report by SINGH et al. [26], who found that patients with persistent eosinophil counts $<2 \%$ had more emphysema progression, which is biologically plausible as neutrophils are known to cause more emphysema. We chose not to include TLC in the multivariable model as it was unfortunately not available in a quarter of the patients. Lung hyperinflation is known to be associated with impaired left ventricular filling [33] and given that TLC values were generally lower in the eosinophilic group, including it in the model might have strengthened the association between eosinophilic COPD and PH.

Unlike asthma, the role of eosinophils in the pathophysiology of COPD is not fully clear [34], but they are associated with more airway remodelling and hyperresponsiveness [35]. The association we found between the eosinophilic COPD phenotype and $\mathrm{PH}$ is novel and remained significant despite adjusting for multiple confounders, using a different cut-off to define eosinophilia and limiting the analysis to the pre-transplant subgroup. Furthermore, patients with COPD-PH had higher blood eosinophil counts than COPD patients

TABLE 5 Eosinophils count in patients with and without COPD-pulmonary hypertension (PH)

\begin{tabular}{|c|c|c|c|}
\hline & COPD-PH & COPD no PH & p-value \\
\hline Patients & 77 & 34 & \\
\hline Max. absolute blood eosinophil count cells $\mu \mathrm{L}^{-1}$ & $263(180-375)$ & $220(157-292.5)$ & 0.050 \\
\hline Max. blood eosinophil percentage \% & $3.4(2-5)$ & $2.4(2-4.1)$ & 0.146 \\
\hline Eosinophil absolute count closest to RHC & $190(140-270)$ & $160(117.5-230)$ & 0.046 \\
\hline At least three eosinophil counts $\geqslant 300$ cells $\mu \mathrm{L}^{-1}$ & $24 / 72$ (33.3) & $2 / 34(5.9)$ & 0.002 \\
\hline Max. eosinophil count $\geqslant 340$ cells $\mu \mathrm{L}^{-1}$ & $26(33.8)$ & $4(11.8)$ & 0.016 \\
\hline
\end{tabular}

Data are presented as $\mathrm{n}$, median (interquartile range), $\mathrm{n} / \mathrm{N}(\%)$ or $\mathrm{n}(\%)$, unless otherwise stated. Max: maximum; RHC: right heart catheterisation. \#: defined as haemodynamic measurement of mean pulmonary artery pressure $\geqslant 25 \mathrm{mmHg}$. 
without PH. There is no reason to suspect that this finding was due to hypoxia, as the eosinophilic group was less likely to require long-term supplemental oxygen.

Although the eosinophilic patients had more left atrial dilation on echocardiogram, it is unlikely that the difference in mPAP and $\mathrm{PH}$ prevalence was driven primarily by more pulmonary venous congestion, as there was no difference in diastolic dysfunction on echocardiogram or PCWP on RHC. Additionally, pre-capillary $\mathrm{PH}$ was more prevalent in the eosinophilic COPD group. Of note, on subgroup analysis including pre-transplant patients only, pre-capillary $\mathrm{PH}$ was numerically more in the eosinophilic COPD group, but was not statistically significant $(39 \%$ versus $21 \%, \mathrm{p}=0.108)$. This could be due to the drop in sample size on subgroup analysis or that the difference in pre-capillary $\mathrm{PH}$ might be driven by nontransplant candidates.

There are few reports in humans linking eosinophils to PAH. A previous report from Sri Lanka found that $>75 \%$ of patients with primary PAH had eosinophilia which was significantly higher than the control groups [11]. Similarly, in humans with schistosomiasis-related PH, high levels of interleukin (IL)-5 and subsequent recruitment of eosinophils are thought to contribute to the development of $\mathrm{PH}$ [12]. In addition, there have been a handful of reports of PH associated with hypereosinophilic disorders [36-38]. Finally, in a single-centre study from Germany, HARBAUM et al. [13] explored the CBC differential in patients with $\mathrm{PAH}$ and found that $>50 \%$ had elevated blood eosinophils. However, they used a much lower cut-off to define eosinophilia $\left(\geqslant 100\right.$ cells $\left.\mu \mathrm{L}^{-1}\right)$. Interestingly, the morphology of the vascular lesions noted in explanted lungs of patients with COPD-PH were comparable to those noted in idiopathic PAH in a report by CARLSEN et al. [39]. Whether eosinophils are biomarkers for $\mathrm{PH}$ or act as a direct vascular modulator in patients with $\mathrm{PH}$ is unclear. DALEY et al. [8] have shown previously that prolonged intermittent airway challenge with extrinsic antigens induced muscularisation of small- to medium-sized pulmonary arteries that was significantly ameliorated by the depletion of IL-13. Furthermore, in a mouse model of PH, WeNG et al. [9] demonstrated that eosinophils were necessary to induce pulmonary vascular remodelling. Specifically, they compared the degree of pulmonary arterial muscularisation in eosinophil-deficient and wild-type mice and found that eosinophil-deficient mice have significantly less pulmonary arterial wall thickening. In addition, they found that mice treated with anti-IL-5 antibodies had markedly lower bronchoalevolar lavage eosinophilia and, more importantly, pulmonary arterial muscularisation compared to mice treated with control antibodies. Additionally, the treatment of pulmonary arterial smooth muscle cells with eosinophilic granule extracts led to two-fold higher proliferation compared to the controls. They also found higher phosphorylation rates of protein kinase B (Akt)1 and extracellular signal-regulated kinase (ERK) in these cells, suggesting that the mechanism linking eosinophil and $\mathrm{PH}$ might be due to activation of Aktl and ERK, both of which are downstream mediators of pulmonary arterial smooth muscle cell proliferation [9]. In another animal model, anti-IL-5 effectively suppressed IL-33 induced pulmonary arterial hypertrophy [10]. Together, these studies suggest that eosinophils may contribute to the development of $\mathrm{PH}$. However, it is more likely that the pathogenesis of $\mathrm{PH}$ in eosinophilic COPD is multifactorial, as $\mathrm{PH}$ has not been reported in eosinophilic asthma, for example. We suspect that other processes such as chronic hypoxaemia, respiratory acidosis, mechanical factors and loss of pulmonary vascular beds due to parenchymal destruction interact together to cause $\mathrm{PH}$ in COPD patients [4].

Our findings may have therapeutic implications, potentially opening the door to study the use of eosinophil-depleting biologics to treat or prevent PH in patients with eosinophilic COPD. In addition, screening for $\mathrm{PH}$ might be more warranted in patients with eosinophilic COPD, but further research is needed. We acknowledge the limitations inherent in retrospective chart review studies. However, we meticulously reviewed the patients' charts and had strict inclusion criteria regarding COPD diagnosis, eosinophilic COPD definition and the need for RHC to define PH. Second, our study subjects were mainly Caucasians with severe and very severe COPD, hence the generalisability of our results to other races/ ethnicities and to those with less severe disease might be limited. The severity of airway obstruction perhaps explains the low rate of bronchodilator response detected in our cohort even in eosinophilic COPD patients. Third, the referral bias perhaps explains the high prevalence of $\mathrm{PH}$ and severe $\mathrm{PH}$ in our patients. However, previous studies have shown that up to $90 \%$ of GOLD IV COPD patients can have mPAP $>20 \mathrm{mmHg}$, which is close to our study [2-4]. Lastly, 17.5\% of the noneosinophilic COPD patients were on and off chronic oral prednisone therapy, which could have caused falsely low eosinophil counts [40]. However, these patients were on low doses ( $\leqslant 10 \mathrm{mg}$ daily), which have been shown to result in no or mild suppression of peripheral eosinophilia [41].

In summary, we found a significant association between eosinophilic COPD and PH. Patients with eosinophilic COPD had higher mPAP and PVR than noneosinophilic COPD. More studies are needed to reproduce these results, investigate the pathophysiological role of eosinophils in COPD-PH and to explore the role of eosinophil-depleting therapy in this patient population. 
Author contributions: B.N. Alzghoul: study conception and design, project administration, institutional review board protocol preparation, statistical analysis, initial draft writing, and manuscript reviewing and editing; B.F. Moreno: data collection, and manuscript reviewing and editing; M. As Sayaideh, S.K. Singh and A. Innabi: manuscript reviewing and editing; R. Reddy and E.S. Papierniak: supervision, study conception and design, and manuscript review and editing; H.M. Alnuaimat: study conception and design, study administration, supervision, and manuscript reviewing and editing. B.N. Alzghoul and H.M. Alnuaimat are the guarantors of the study. All authors reviewed and approved the final manuscript.

Data availability: Data are available upon request from the corresponding author.

Conflict of interest: None declared.

\section{References}

1 World Health Organization (WHO). Global Health Estimates. www.who.int/healthinfo/global_burden_disease/en/ Date last accessed: 31 August 2020.

2 Seeger W, Adir Y, Barberà JA, et al. Pulmonary hypertension in chronic lung diseases. J Am Coll Cardiol 2013; 62: D109-D116.

3 Nathan SD, Barbera JA, Gaine SP, et al. Pulmonary hypertension in chronic lung disease and hypoxia. Eur Respir J 2019; 53: 1801914 .

4 Chaouat A, Bugnet A-S, Kadaoui N, et al. Severe pulmonary hypertension and chronic obstructive pulmonary disease. Am J Respir Crit Care Med 2005; 172: 189-194.

5 Global Initiative for Chronic Obstructive Lung Disease. Global Strategy for the Diagnosis, Management and Prevention of COPD. 2020 Available from: www.goldcopd.org/

6 Harries TH, Rowland V, Corrigan CJ, et al. Blood eosinophil count, a marker of inhaled corticosteroid effectiveness in preventing COPD exacerbations in post-hoc RCT and observational studies: systematic review and meta-analysis. Respir Res 2020; 21: 3.

7 Watz H, Tetzlaff K, Wouters EFM, et al. Blood eosinophil count and exacerbations in severe chronic obstructive pulmonary disease after withdrawal of inhaled corticosteroids: a post-hoc analysis of the WISDOM trial. Lancet Respir Med 2016; 4: 390-398.

8 Daley E, Emson C, Guignabert C, et al. Pulmonary arterial remodeling induced by a Th2 immune response. J Exp Med 2008; 205: 361-372.

9 Weng M, Baron DM, Bloch KD, et al. Eosinophils are necessary for pulmonary arterial remodeling in a mouse model of eosinophilic inflammation-induced pulmonary hypertension. Am J Physiol Lung Cell Mol Physiol 2011; 301: L927-L936.

10 Ikutani M, Ogawa S, Yanagibashi T, et al. Elimination of eosinophils using anti-IL-5 receptor alpha antibodies effectively suppresses IL-33-mediated pulmonary arterial hypertrophy. Immunobiology 2018; 223: 486-492.

11 Obeyesekere I, de Soysa N. "Primary" pulmonary hypertension, eosinophilia, and filariasis in Ceylon. $\mathrm{Br}$ Heart J 1970; 32: 524-536.

12 de Jesus AR, Silva A, Santana LB, et al. Clinical and immunologic evaluation of 31 patients with acute schistosomiasis mansoni. J Infect Dis 2002; 185: 98-105.

13 Harbaum L, Baaske KM, Simon M, et al. Exploratory analysis of the neutrophil to lymphocyte ratio in patients with pulmonary arterial hypertension. BMC Pulm Med 2017; 17: 72.

14 Celli BR, MacNee W, Agusti A, et al. Standards for the diagnosis and treatment of patients with COPD: a summary of the ATS/ERS position paper. Eur Respir J 2004; 23: 932-946.

15 Labaki WW, Martinez CH, Martinez FJ, et al. The role of chest computed tomography in the evaluation and management of the patient with chronic obstructive pulmonary disease. Am J Respir Crit Care Med 2017; 196: $1372-1379$.

16 Chapman KR, Hurst JR, Frent S-M, et al. Long-term triple therapy de-escalation to indacaterol/glycopyrronium in patients with chronic obstructive pulmonary disease (SUNSET): a randomized, double-blind, triple-dummy clinical trial. Am J Respir Crit Care Med 2018; 198: 329-339.

17 Yun JH, Lamb A, Chase R, et al. Blood eosinophil thresholds and exacerbations in chronic obstructive pulmonary disease. J Allergy Clin Immunol 2018; 141: 2037-2047.

18 Culver BH, Graham BL, Coates AL, et al. Recommendations for a standardized pulmonary function report. An official American Thoracic Society technical statement. Am J Respir Crit Care Med 2017; 196: 1463-1472.

19 Hankinson JL, Odencrantz JR, Fedan KB. Spirometric reference values from a sample of the general U.S. population. Am J Respir Crit Care Med 1999; 159: 179-187.

20 Rudski LG, Lai WW, Afilalo J, et al. Guidelines for the echocardiographic assessment of the right heart in adults: a report from the American Society of Echocardiography endorsed by the European Association of Echocardiography, a registered branch of the European Society of Cardiology, and the Canadian Society of Echocardiography. J Am Soc Echocardiogr 2010; 23: 685-713.

21 LaFarge CG, Miettinen OS. The estimation of oxygen consumption. Cardiovasc Res 1970; 4: 23-30.

22 Gerges C, Gerges M, Lang MB, et al. Diastolic pulmonary vascular pressure gradient: a predictor of prognosis in "out-of-proportion" pulmonary hypertension. Chest 2013; 143: 758-766.

23 Vedel-Krogh S, Nielsen SF, Lange P, et al. Blood eosinophils and exacerbations in chronic obstructive pulmonary disease. The Copenhagen General Population Study. Am J Respir Crit Care Med 2016; 193: 965-974.

24 D'Andrea A, Naeije R, Grünig E, et al. Echocardiography of the pulmonary circulation and right ventricular function: exploring the physiologic spectrum in 1,480 normal subjects. Chest 2014; 145: 1071-1078.

25 Tashkin DP, Wechsler ME. Role of eosinophils in airway inflammation of chronic obstructive pulmonary disease. Int J Chron Obstruct Pulmon Dis 2018; 13: 335-349.

26 Singh D, Kolsum U, Brightling CE, et al. Eosinophilic inflammation in COPD: prevalence and clinical characteristics. Eur Respir J 2014; 44: 1697-1700.

27 Pavord ID, Lettis S, Locantore N, et al. Blood eosinophils and inhaled corticosteroid/long-acting $\beta$-2 agonist efficacy in COPD. Thorax 2016; 71: 118-125. 
Barnes NC, Sharma R, Lettis S, et al. Blood eosinophils as a marker of response to inhaled corticosteroids in COPD. Eur Respir J 2016; 47: 1374-1382.

29 Wedzicha JA, Banerji D, Chapman KR, et al. Indacaterol-glycopyrronium versus salmeterol-fluticasone for COPD N Engl J Med 2016; 374: 2222-2234.

30 Siddiqui SH, Guasconi A, Vestbo J, et al. Blood eosinophils: a biomarker of response to extrafine beclomethasone/ formoterol in chronic obstructive pulmonary disease. Am J Respir Crit Care Med 2015; 192: 523-525.

31 Wu H-X, Zhuo K-Q, Cheng D-Y. Prevalence and baseline clinical characteristics of eosinophilic chronic obstructive pulmonary disease: a meta-analysis and systematic review. Front Med 2019; 6: 282.

32 Schumann DM, Tamm M, Kostikas K, et al. Stability of the blood eosinophilic phenotype in stable and exacerbated COPD. Chest 2019; 156: 456-465.

33 Watz H, Waschki B, Meyer T, et al. Decreasing cardiac chamber sizes and associated heart dysfunction in COPD: role of hyperinflation. Chest 2010; 138: 32-38.

34 Bafadhel M, Pavord ID, Russell REK. Eosinophils in COPD: just another biomarker? Lancet Respir Med. 2017; 5: 747-759.

35 George L, Brightling CE. Eosinophilic airway inflammation: role in asthma and chronic obstructive pulmonary disease. Ther Adv Chronic Dis 2016; 7: 34-51.

36 Konno R, Tatebe S, Shirai T, et al. Immunosuppressive therapy ameliorates refractory vasospastic angina, severe pulmonary hypertension, and bronchiolitis in a patient with eosinophilic granulomatosis with polyangiitis: a case report. Eur Heart J Case Rep 2018; 2: yty050.

37 Ibe T, Wada H, Sakakura K, et al. A case of pulmonary hypertension associated with idiopathic hypereosinophilic syndrome. Int Heart J 2018; 59: 887-890.

38 Kawashima A, Kimura A, Katsuda S, et al. Pulmonary vasculitis with hypereosinophilia and episodic pulmonary hypertension: report of three siblings. Pathol Int 1995; 45: 66-74.

39 Carlsen J, Hasseriis Andersen K, Boesgaard S, et al. Pulmonary arterial lesions in explanted lungs after transplantation correlate with severity of pulmonary hypertension in chronic obstructive pulmonary disease. J Heart Lung Transplant 2013; 32: 347-354.

40 Ortega $\mathrm{H}$, Llanos J-P, Lafeuille $\mathrm{M}-\mathrm{H}$, et al. Effects of systemic corticosteroids on blood eosinophil counts in asthma: real-world data. J Asthma 2019; 56: 808-815.

41 Serra-Bonett N, Al Snih S, Rodriguez MA. Effect of low-dose prednisone on leukocyte counts and subpopulations in patients with rheumatoid arthritis. J Clin Rheumatol 2009; 15: 148-149. 